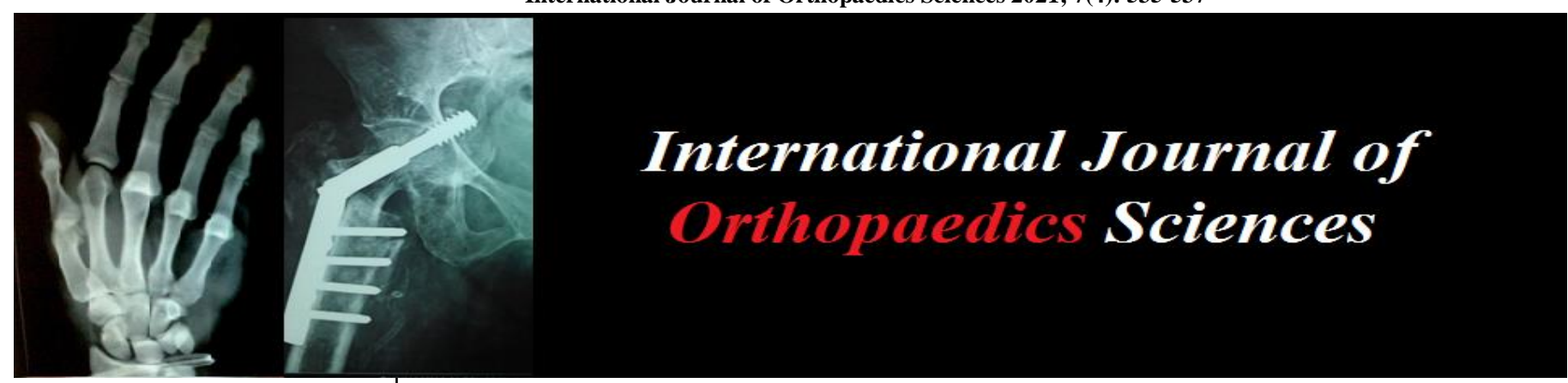

E-ISSN: 2395-1958

P-ISSN: 2706-6630

IJOS 2021; 7(4): 535-537

(C) 2021 IJOS

www.orthopaper.com

Received: 04-06-2021

Accepted: 11-07-2021

Dr. Govind Mohan Jee Associate Professor,

Department of Orthopaedics, J.L.N.M.C. Bhagalpur, Bihar, India

Dr. Nitin Kumar

Senior Resident,

Department of Orthopaedics, JLNMCH, Bhagalpur, Bihar, India

Dr. Dilip Kumar Singh HOD,

Department Orthopaedics, JLNMCH, Bhagalpur, Bihar, India
Corresponding Author: Dr. Govind Mohan Jee Associate Professor,

Department of Orthopaedics, J.L.N.M.C. Bhagalpur, Bihar, India

\section{Close enders nailing as internal bracing for acute humeral diaphyseal fractures in children and adolescents}

\author{
Dr. Govind Mohan Jee, Dr. Nitin kumar and Dr. Dilip Kumar Singh
}

DOI: https://doi.org/10.22271/ortho.2021.v7.i4h.2928

Abstract

Background: In children diaphyseal fractures of humerus are most commonly treated by close reduction and cast immobilisation. Surgical treatment is preferred only in the cases recalcitrant to conservative treatment (1).

Aim of the study: The present prospective study is to analyse the functional outcome of close enders nailing in the management of diaphyseal fracture of humerus in children and adolescents

Material and Methods: Thirty patients with diaphyseal fracture of humerus in children and adolescents were treated with close enders nailing. In our series, mean age of the patients was 13.05 years (10 to 16 year).Boys dominated our series $(\mathrm{n}=20$ i.e.66.66\%) and right side $(\mathrm{n}=22$ i.e.73.33\%) was more commonly involved in both sexes. All the fractures were stabilised with close reduction and internal fixation with antegrade Enders nailing.

Result: Minimal follow up was six month. Timely union was observed in all except three in an average of 10.81 weeks. In two cases union was delayed (14 and 16 weeks). One case faced nonunion and was treated with open reduction and internal fixation with dynamic compression plate with bone grafting.

Observation: Functional outcome was evaluated using DASH Score. We had 27 excellent, 02 good and 01 poor result in our series.

Conclusion: Close enders nailing is very demanding, safe and efficient method of treatment of acute humeral diaphyseal fracture in children and adolescents, offers a biological method of fracture healing and can be considered as internal bracing(2).

Level of evidence - IV (case series).

Keywords: Close enders nailing, humeral fracture, children

\section{Introduction}

Fracture shaft of humerus is a common injury and is seen in children and adolescent. Conservative treatment is still a favoured treatment modality for this specially in children and adolescent but it has some demerits like residual deformity and plaster related complications. On the other hand, surgical treatment also has some inherent complications like infection, nerve injury and non-union ${ }^{[1,7]}$. The purpose of the surgical treatment is anatomical reduction, stable fixation, preservation of vascularity and pain free mobilisation of adjacent muscles and joints to prevent development of fracture diseases. Out of various surgical procedures for fracture shaft of humerus, close Enders nailing has emerged as an excellent procedure specially in children and adolescent. Shorter operative time, less blood loss and less disruption of periosteal and endosteal blood supply are known advantages of close enders nailing of humeral shaft fracture ${ }^{[1]}$. It can be considered as internal bracing of the fracture. Above all it can be offered to and is useful the patients with polytrauma.

\section{Aim of the study}

The aim of the study was to analyse the outcome and complications of close enders nailing in the management of acute diaphyseal fracture of humerus in children and adolescent.

\section{Material and Methods}

This prospective study was carried out between January 2017 to December 2019. 
Our series consisted of thirty patients of fracture shaft of humerus in children and adolescents. Patients with fracture shaft of humerus except with extensive compounding and that with neurological injuries were selected. Patient counselling and informed consent were mandatory in our series. Mean age was 13.5 years (range11-16 years). Boys dominated our series $(n=20$ i.e.66.66\% $)$ and right side was more commonly involved $(\mathrm{n}=22$ i.e. $73.33 \%)$. All of them were properly investigated for their fitness for general anaesthesia or scalene block. Proper preoperative clinical and radiographic evaluation was carried out. Steps of procedure including patient positioning and surgical procedure was discussed and documented. In our series, all patients were treated with antegrade close enders nailing. All the patients were operated with in 72 four hours of the injury.

\section{Surgical procedure}

General anaesthesia or scalene block was used in the procedure as decided by anaesthetist. Supine position was preferred on fracture table with radiolucent top. Operative limb was draped after proper antiseptic scrub. Fixation of the fracture was carried out following standard operative technique of antegrade humeral enders nailing under C-Arm control. In most of the patients two or three enders nails of appropriate sizes were required for stability. Tips of the nails were buried in proximal humerus to avoid rotator cuff impingement. Stability was assessed and depending on the stability operated limb was supported in arm sling or brace or slab only for arm. The patients were advised supervised physiotherapy at shoulder and elbow as soon as the pain subsided.

\section{Postoperative care}

In immediate postoperative period, limb elevation was ensured. First dressing change was done on third postoperative day. Sutures were removed on $14^{\text {th }}$ day.

\section{Follow up}

Patients were followed up at 2 week, 4 week, 8 week, 16 week, 24 week and 28 week. Radiographic analysis was performed in immediate postoperative period and at each follow up with special attention to alignment of fragments, extent of callus formation and implant integrity. Clinical examination was also done at each follow up and affected limb was inspected for swelling, infection and range of movement at shoulder and elbow and DASH score was calculated for each patient.

Table 1: Shows Age distribution of the patient

\begin{tabular}{|c|c|}
\hline Age group (years) & Number of patients (\%) \\
\hline 11 & $03(10 \%)$ \\
\hline 12 & $08(26.66 \%)$ \\
\hline 13 & $06(20 \%)$ \\
\hline 14 & $04(13.33 \%)$ \\
\hline 15 & $03(10 \%)$ \\
\hline 16 & $06(20 \%)$ \\
\hline
\end{tabular}

Mean age of the patient was 13.5 years (range $11-16$ years)

Table 2: Shows findings of follow up x-ray

\begin{tabular}{|c|c|c|}
\hline Findings of x-ray & Number of weeks) & No. of patients (\%) \\
\hline Timely union & $8-12$ weeks & $27(90.00 \%)$ \\
\hline Delayed union & $13-18$ weeks & $02(06.66)$ \\
\hline Non-union & & $01(03.33 \%)$ \\
\hline
\end{tabular}

Median healing time was 11 weeks and mean was 11.10 week (range was 08 to 18 weeks)
Table 3: Shows complications encountered in our series

\begin{tabular}{|c|c|}
\hline Complications encountered & Number of patients (\%) \\
\hline infection & $00(0.00)$ \\
\hline Delayed union & $02(6.66)$ \\
\hline Mal-union & $00(0.00)$ \\
\hline Non-union & $01(3.33)$ \\
\hline Nail back out & $02(6.66)$ \\
\hline Stiffness of elbow & $00(0.00)$ \\
\hline Stiffness of shoulder & $03(10.00)$ \\
\hline Shoulder pain & $04(13.33)$ \\
\hline Need for second surgery & $01(3.33)$ \\
\hline Nerve injuries & $00(0.00)$ \\
\hline
\end{tabular}

Table 4: Shows DASH score at final follow up

\begin{tabular}{|c|c|c|}
\hline CM Score & Result & Number of patient (\%) \\
\hline $0-5$ & excellent & $27(90.00)$ \\
\hline $6-15$ & Good & $02(06.66)$ \\
\hline $15-35$ & Fair & $00(00.00)$ \\
\hline$>35$ & Poor & $00(00.00)$ \\
\hline
\end{tabular}

DASH score was not calculated in one patient as that went into nonunion

\section{Observation}

Radiographic union was defined as presence of complete osseous bridge across the fragments in both AP and lateral view. In our series, all except three patients showed union in expected time (10 -12 weeks). In two patients union was delayed and was observed at 14-16 weeks. In one case there was non-union and was treated by open reduction and internal fixation with dynamic compression plating along with bone grafting. Pain was found to be most common complication $(n=4,13.33 \%)$.Need for second surgery was observed in only one patients $(3.33 \%)$ cases. There were no intraoperative complication i.e. neurologic or vascular. We had 27 Excellent, 02 Good and 01poor results in our series ( $p$ value $<0.001$ ).

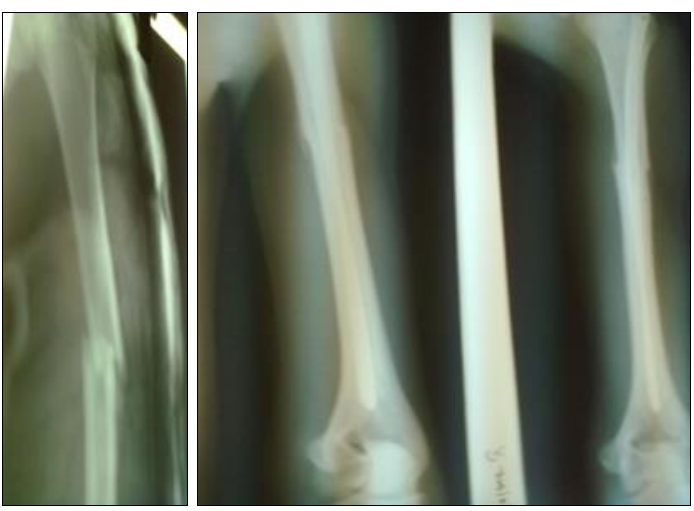

Fig 1: Case 1, Preoperative and postoperative x-ray

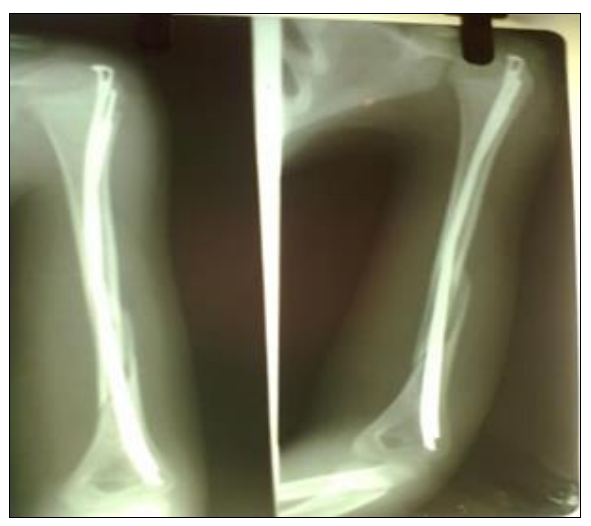

Fig 2: Case 2, Postoperative X-ray 


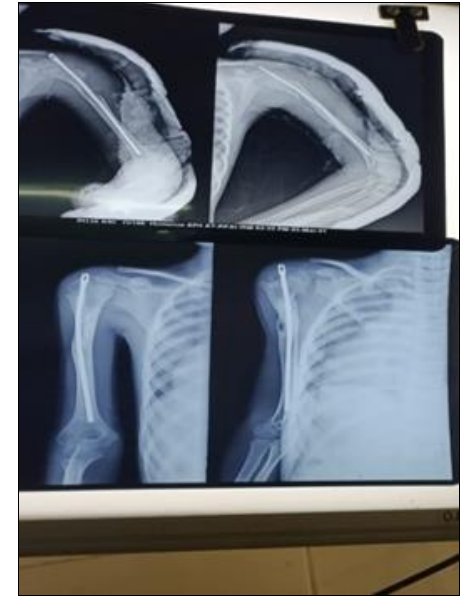

Fig 3: Case no 3 Postoperative x-rays

\section{Discussion}

Non-operative treatment still remains the first favoured treatment modality for most humeral diaphyseal fractures ${ }^{[4]}$. Enders nailing can be performed safely in selected cases in our series all the patients were operated with antegrade nailing of humerus. Although proximal entry point for antegrade nailing of humerus has been reported to be associated with rotator cuff injury and impaired shoulder function ${ }^{[5,6]}$, we did not encounter these complications. The results in our series showed almost identical range of movement at operated and contralateral non-operated limb except in one case.

Hall RF et al. in his series of 89 patients of humeral shaft fracture reported average time of union to be 7.2 weeks ${ }^{[3]}$.

Shazar $\mathrm{N}$ et al. performed a retrospective review of 89 patients treated with enders nail and reported good result in $74 \%$ of patients and union in $91.5 \%{ }^{[10]}$.

Rohan Memon et al. in his series of 20 cases reported union within 12-14 weeks in $70 \%$ cases with DASH Score being in the normal range in $65 \%$ of cases.

\section{Conclusion}

At the end of the study, it can be concluded that close enders nailing of humerus is an efficient, minimally invasive, cost effective and safe procedure to address diaphyseal fracture of humerus in children and adolescent. It provides congenial environment for biological healing of fracture. Shorter operative time, less blood loss, less disruption of endosteal and periosteal blood supply and less incidence of infection are its known advantages ${ }^{[9]}$. It can be offered to the patients of fracture shaft of humerus in this age group and is specially suited for polytrauma patients. However only fractures that are recalcitrant to close reduction should be considered for this method.

\section{Source of funding: None}

\section{Conflict of interest}

There was no conflict of interest

\section{References}

1. Hall RF, Pankovich AM. Enders nailing of acute fracture of humerus. A study of closed fixation by intramedullary nails without reaming. $\mathbf{J}$ Bone Joint Surg. Am 1987;69(4):558-67.

2. Huber RI, Keller HW, Huber PM, Rehm KE. Flexible intramedullary nailing as fracture treatment in children. J Paedriatic Orthop 1996;16:602-601.
3. Uhthoff HK, Poitras P, Backman DS. Internal plate fixation of fractures: short history and recent developments. Journal of Orthopaedic Science 2006;11(2):118-26.

4. Sarmento A, Zagorski JB, Zych GA, Latta LL, Capps CA. Functional bracing for treatment of fracture of humeral diaphysis. J Bone Joint Surg 2000;82-A:478486.

5. Scheerlinck T, Handelberg F. Functional outcome after intramedullary nailing of humeral shaft fractures; comparison between retrograde Marchetti-Vicenzi and undreamed AO ante grade nailing J Trauma 2002;52:6071.

6. Williams PR, Shewring D. Use of an elastic intramedullary nail in difficult humeral fractures. Injury 1998;29:661-670.

7. Stannard JP, Harris HW, McGwin G Jr, Volgas DA, Alonso JF. Intramedullary nailing of humeral shaft fracture with a locked flexible nail. J Bone Joint Surg 2003m, 85-A2103-2110.

8. Spina N, Mus L, Basile G, Santamaria S Flexible intramedullary classical nailing in childhood: use in fractures of femur and humerus. Chir Organi Mov 1998;83:277-283.

9. Shazar N, Brumback RJ, Vanco B. Treatment of humeral fracture by close reduction and retrograde intramedullary Enders nails. Orthopaedics 1998;21(6):641-46.

10. Rohan Memon, Ketan Parmar. Clinical outcome of treatment of fractures of lower third shaft humerus by enders nail in adult age group. IJOS 2020;6(1):88-91. 